individual susceptibility to fatigue and capacity to recover, and of detecting disturbances in fitness from other causes such as loss of sleep, worry and all mental states that distract attention, etc.; and (7) as a means of training eyes to greater oculomotor and accommodative facility.

\title{
REFERENCES
}

1. Fechet, J. E.-“"Those airplane crashes ; how they can be prevented." Flight Surgeon Topics, School of Aviation Medicine, Randolph Field, Texas, Vol. I, pp. 44-48, 1937.

2. FERREE, C. E. and RAND, G.- "The inertia of the eye for clear seeing : t different distances." A study of ocular functions with special reference to aviation. Amer. Jl. Ophthal., Vol. I, pp. 764-776, 1918.

3. FERREE, C. E. and RAND, G.-An instrument for measuring dvnamic speed of vision, speed of accommodation and ocular fatigue." Arch. of Ophthal., Vol. XV, pp. 1072-1087, 1936.

4. Robertson, C. J.- "Measurement of the speed of adjustment of the eye to near and far vision." U.S. Naval Med. Bull., Vol. XXXII, pp. 275-283, 1934 ; "A comparative study of the measurement of the speed of adjustment of the eye for near and far vision." Ibid., Vol. XXXIII, pp. 187-205, 1935; "Measurement of speed and adjustment of eye for near and far vision." Arch. of Ophthal., Vol. XIV, pp. 82-89, 1935; " Measurement of speed of adjustment of eye to near and far vision, a further study." Ibid., Vol. XV, pp. 423-434, 1936: " Effect of fatigue on the adjustment of the eye to near and far vision." 'Ibid., Vol. XVII, pp. 859-876, 1937.

5. FERREE, C. E. and RAND, G.- "Lamp for determination and measurement of the preferred intensity of light for reading and for other work." Arck. of Ophthal., Vol. XII, pp. 45-59, 1934.

6. Robertson, C. J.- " Measurement of speed of adjustment of eye to near and far vision, a further study." Arch. of Ophthal., Vol. XV, p. 433, 1936.

7. Robertson, C. J.- "Effect of fatigue on the adjustment of the eye to near and far vision." Arch. of Ophthal., Vol. XVII, pp. 859-876, 1937.

8. FERREE, C. E.- "Tests for the efficiency of the eye under different systems of illumination and a preliminary study of the causes of discomfort." Trans. Illum. Eng. Soc., Vol. VIII, pp 40-57, 1913.

FERREE, C. E. and RAND, G.- "An investigation of the reliability of the "li " test "-discussion of paper by Luckiesh, Cobb and Moss. Trans. Illum. Eng. Soc., Vol. XXII, pp. 52-75, 1927.

\section{RARE OCULAR DEVELOPMENTAL ANOMALIES IN ASSOCIATION WITH CONGENITAL AND ACQUIRED BLINDNESS Clinical "proof" of vitreous development}

BY

\section{J. HORTON YOUNG}

\author{
CHELMSFORD
}

THE following history of a blind patient who attended my ophthalmic clinic illustrates the complexities which underlie certain types of cases presenting themselves for blindness certification. 
In this case there had been an "arrest" of development of certain structures within the left globe. This eye was congenitally blind. The right eye was remarkable for the complex factors which ultimately caused the eye to become blind and for the fact that the same agency was responsible for the ultimate death of the patient.

Present History and Course.-The patient H. W., born January 3,1918 , attended my clinic on December 12, 1939, and subsequently for certification under the Blind Persons Act. He was totally blind. The right eye became blind three years previously following a severe attack of pain and inflammation in this eye. As the fundus was not seen and the eye presented the appearance of posterior synechiae with gross generalised enlargement of the globe a provisional diagnosis of uveitis, complicated by secondary glaucoma, was made. The left eye was congenitally blind and exhibited developmental anomalies which in view of their importance I proceeded to record " in minutiae."

At the same time the patient's family history was investigated in an endeavour to find an hereditary basis for these anomalies.

The right eye necessitated removal and this was advised. Shortly afterwards the patient was admitted to the Old Church

Genealogy.

$$
\begin{aligned}
& \square=\text { Bilateral Blindness: Congenital. } \\
& \square\}=\text { Normal. } \\
& \bigotimes\}=\text { Severe Myopia. } \\
& \bigotimes\}=\text { Myopia and Mental Deficiency of Congenital origin. } \\
& \text { 春 = Patient, Congenital and Acquired Blindness. } \\
& E\}=\text { Mental Deficiency. } \\
& \square=\text { Unilateral Blindness: Cause Unknown. }
\end{aligned}
$$




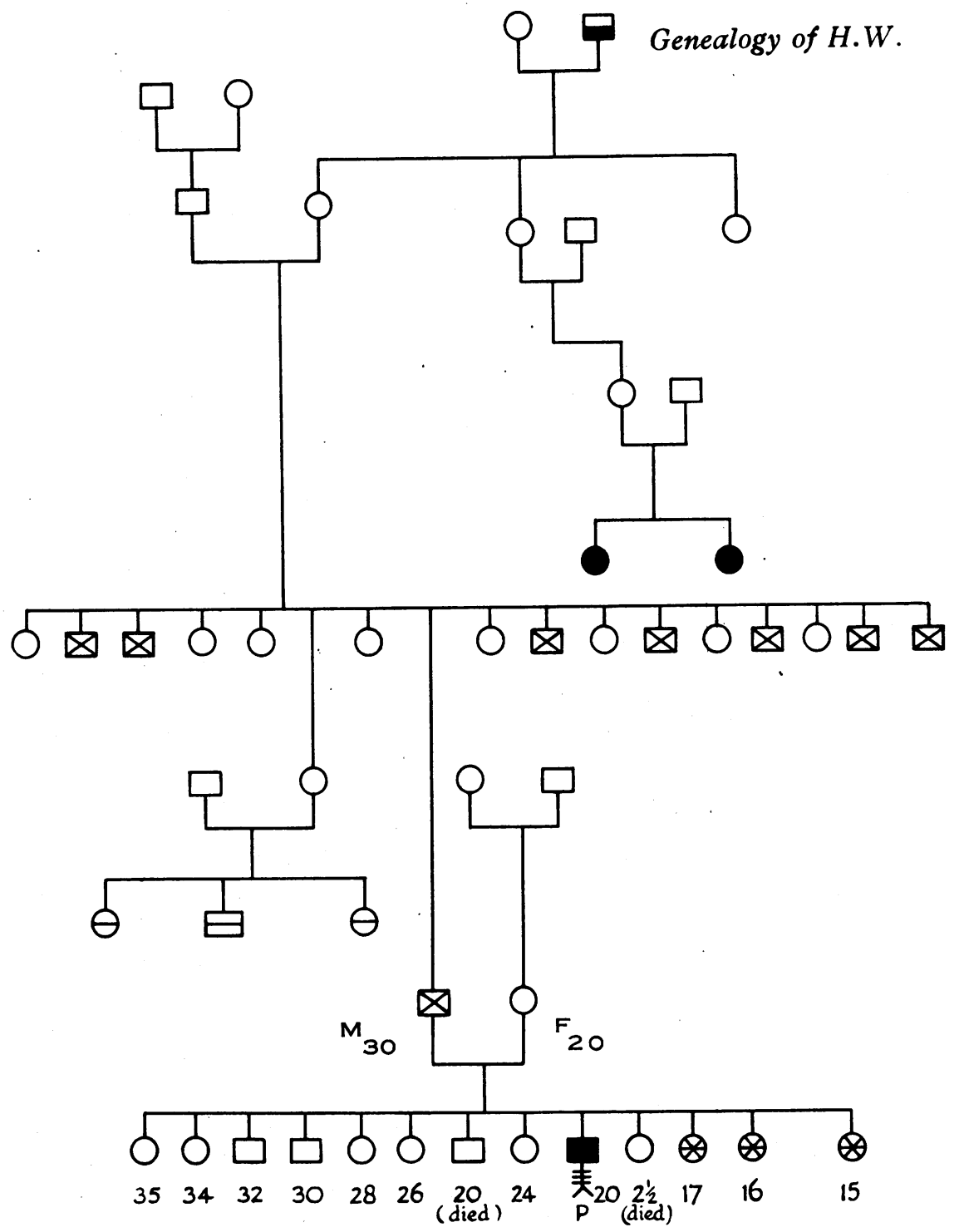

Hospital, Romford, where the operation was performed under evipan anaesthesia. Subsequently the patient developed aphasia, a rise in temperature, rash on the body, right hemiplegia, and cerebral embolism, dying 14 days later. A post-mortem examination was made to establish the cause of death.

Previous History, Illnesses, etc.-Birth quite normal, no history of trauma, difficulty or forceps. Six years ago developed a keratitis which necessitated carbolisation. Four years ago had 
a dental operation under G.A. which was followed by aphasia which cleared up without any trouble. The patient was discharged as healthy.

There was no history of rheumatism. The right eye became suddenly blind one year later (three years ago), following a severe attack of inflammation in it. Following this the right eye had enlarged slowly at first, but during the last eighteen months it had grown rapidly in size.

This is best studied from the schematic diagram. I have endeavoured to make this as accurate as possible, but the prevailing circumstances (family attitude) were against individual interrogation.

It will be noted that there is an extensive history of severe myopia in this family. Mental deficiency of congenital origin (poor cerebral development) is to be found in a number of cases. Bilateral blindness of " congenital " origin was present in two children on one side of the family. The blindness in one instance being given as "ganglio-neuroma" and in the other due to severe myopia.

General Appearance, etc.-Patient stands well erect, head turned to the left side, somewhat undersized in stature, physical age 15 to 16 years (actual age 20 years), slight pallor of the face, head squarish, but no obvious bossing, facial asymmetry present with the left orbit and globe lower than the right. Palpation of the left orbital margin showed that it appeared to be more spherical than the right orbit. This may have been due to the position of the left eye which had assumed a " normal" position of divergency, being a congenitally blind eye. The teeth were irregular, some peg-like, but no evidence of Hutchinson's teeth. There was no suggestion of a defective bridge or rhagades. The arms were long in proportion to the body, muscles were firm and strong, and the hands and feet were on the large side. Dyspnoea, tachycardia, club fingers or other signs of congenital abnormality apart from the condition of the left eye were absent. (See also postmortem findings.)

Ocular findings.-In view of its importance the left eye will be discussed first. Congenitally blind. No P.L. Tension normal. The anterior chamber was normal in depth (as judged by the rudimentary iris position), and was filled with vitreous. The anterior and posterior chambers were in direct communication as there was luxation (ectopia vera) of the lens. The vitreous ge! was solid and perfectly transparent. There were no floaters. The optical and physical perfection of the vitreous was heightened by the partial aniridia and the malposition of the lens. The rudimentary iris was represented by a small ring of tissue one and a 
番 $\stackrel{\circ}{7}$

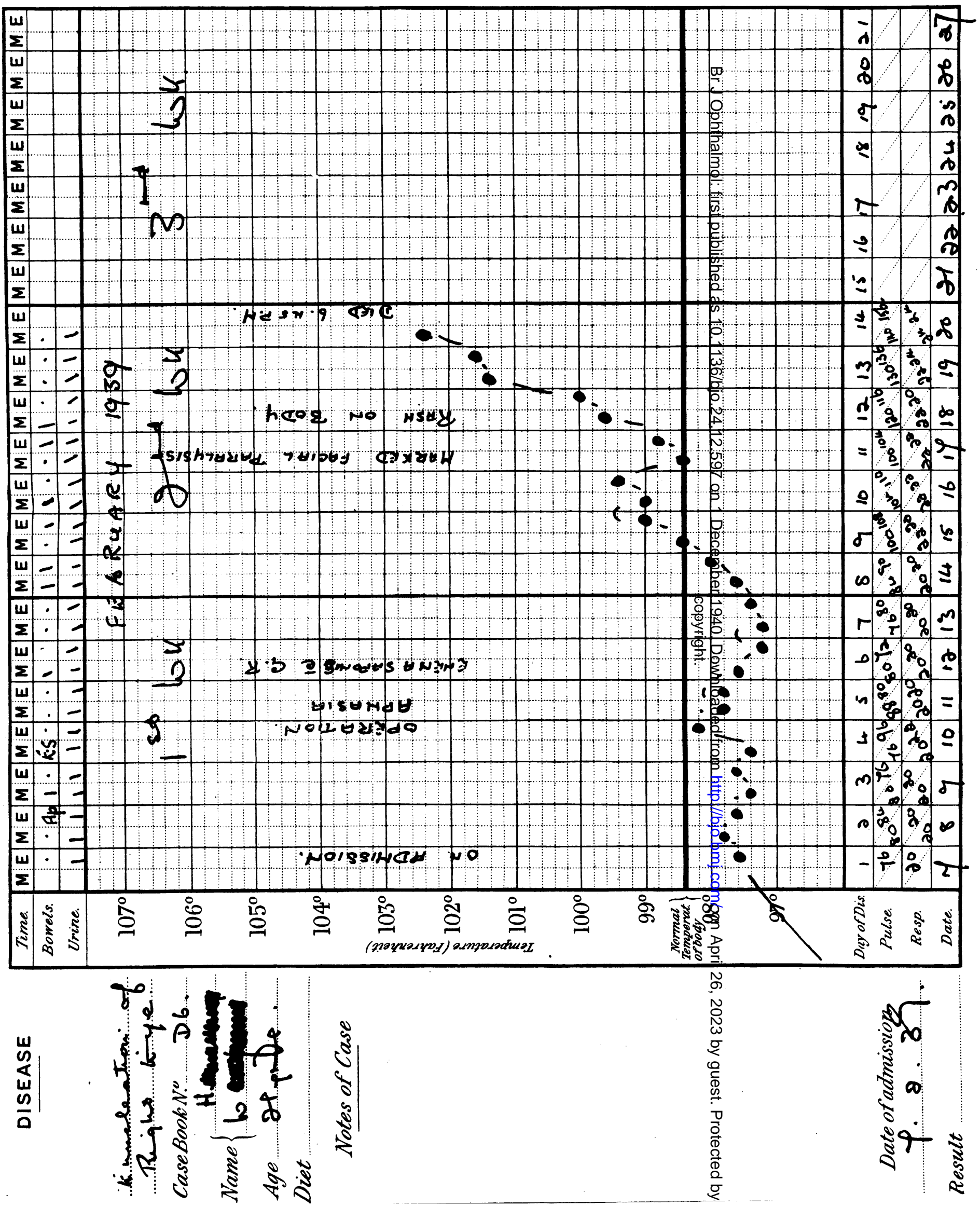


half mms. wide attached to a zone of greyish tissue-the rudimentary ciliary body-running circularly around the globe. It is highly probable that the pars reticularis and the canal of Schlemm had also suffered a similar maldevelopment in association with these two structures.

The lens was abnormally placed within the fundus in the postinfero-temporal region, which, in view of the fact that it was notched and possessed a peculiar physical structure, I consider was a true ectopia. This lens was much smaller than normal, notched, sphero-conoid in shape with a dorsal groove terminating anteriorly in a kidney-shaped base which was of a furry matt-white colour. From the lens notch a fine leash of blood vessels made their way to the region of the equator where they made contact with another vessel about a peripheral retino-dialysis. Apart from the kidney-shaped base the remainder of the lens capsule (a small part only could be seen) possessed a thickened, dirty-grey, greasy parchment appearance and seemed only relatively translucent.

The remainder of the fundus presented many anomalies. The optic nerve head was absent, there being a complete absence of nerve fibres here and throughout the retina. The optic cup was of extremely narrow bore and of great depth (no base could be seen) and lacked a lamina cribrosa. The depth was accentuated by the sharp-cut edges of the cup and the narrowness of the bore. The position of the disc was more up and in than in a normal globe.

There were no retinal vessels proceeding from the optic cup and segmentally distributed as in the normal retina, which was completely avascular except for a single flattened vessel. This blood vessel was arterio-venous in colour, completely devoid of a glial covering which indicated its adventitious nature and was not developed in normal relation to the retina. This ribbon-like vessel rose from the depths of the cup, ascended some distance into the vitreous, curled upon itself twice and then descended to the retinal level on the nasal side and, dividing dichotomously, ended in an oval mass of irregular pigment. This pigment had a burnished gun-metal appearance which I mistook at first for a primitive tapetum. The choroidal vessels, however, were hidden over this mass and it appeared as if there had been an attempt at normal retinal formation. There were no white, patchy spots and there was no evidence in the neighbouring choroidal vessels that this had been a zone of past choroiditis.

The significance of this pigment was very obvious since this nasal area was the only portion of the fundus which had a suggestion of choroid and this was of primitive type showing only large vessels, a complete absence of choriocapillaris and the 
medium-sized vessels. Apart from the zone of pigment aggregate, the pigment distribution was of a fine, very scattered type (sand grains). The retina on the temporal side was avascular also, and here there was an absence of choroid and pigment of any kind. There had been no differentiation of a macular zone. I tried hard to find evidence of a past or present retinal circulation, which I thought might exhibit themselves in the form of attenuated fibrous lines, as I wanted to be quite sure that the phenomenon of this avascularity was not that of a secondary functional atrophy. This point was of importance since the retina was detached on this temporal side in association with a retinodialysis of an unusual type. The phenomena observed in relation to this detachment are worthy of special mention and I shall describe them in detail.

The detached retina in this area consisted of two large, radiating folds spreading fan-wise from the region near the disc, both crests running out to the dialysis, through which the vitreous had " herniated" (or differentiated) without disturbance of its transparency. Commencing from a zone somewhat anterior to the equator, a fine leash of supporting stroma passed down towards the dialysis and divided into two columns, one column passing along the free edge of the dialysis, but jumping from crest to crest, leaving the trough, between the two main folds, untouched. This supporting stroma carried very fine vessels to the underlying retina. The stroma continued its path vertically downwards to rejoin the other branch of fibrous tissue which followed the course of that portion of the peripheral retina which had remained attached to the " ora serrata," which was of a grey colour. Where the supporting stroma touched the crests, fine bundles of fibrous tissue passed down the folds, accompanied by fine blood vessels, to the troughs, thus giving the two retinal folds the appearance of fine veined leaves. The dialysis was so large that it was possible to look between the pillars of supporting stroma and through the dialysis, and view the matt-white sclera, which was completely devoid of any sign of past or present blood vessels. The effect of looking through these pillars into this postretinal "cavern " with my luminous ophthalmoscope, was like looking into a lighted fairy grotto, so beautiful was the play of colours between the faint, lake-green retina, the faint pearly-blue iridescence of the supporting stroma with its accompanying fine reddish blood vessels, and the brilliant matt-white sclera. The whole effect, reinforced by the heightened reflexes, was quite unlike anything I had ever seen before. With regard to the radiating retinal folds, these were "ironed out" and lacked the cross-dimpling seen in ordinary dialysis. (The analogy would be 
the creases in one's sleeve on flexing the elbow.) It appeared that the retino-dialysis was the direct result of slow contracture of the supporting stroma. Probably also the effect may have been contributed to by the absence of the normal retinal vessels, with their attendant elastic tissue, and in part to the thinned retina which lacked neuronal development.

\section{Discussion}

In a congenitally blind eye of this type in which there are unusual developmental anomalies there must exist clues which point to the mode of development of some of the structures in the normal eye. The following is a brief summary of the extraordinary clinical phenomena observed in this eye.

(1) Primitive optic " disc"-absence of nerve head-no lamina cribrosa-narrow-bore optic cup, great depth.

(2) Complete absence of the normal retinal vascular system in the non-detached and the detached portions of the retina and the optic cup-complete absence of neuronal development.

(3) Partial achoroidia temporal side and a maldeveloped choroid nasal side in association with which there was pigment deposition of unusual type.

(4) Rudimentary ciliary body (grey colour due to absence of pigment epithelium, normally developed from the neural ectoderm).

(5) Partial aniridia.

(6) Luxatio lentis (probable ectopia vera), associated with abnormal physical shape and structure with an auxiliary blood supply.

(7) A perfect vitreous.

(8) No evidence of any remains of the primitive hyaloid vascular system. (This negative evidence is valuable since retinal circulation is an outgrowth from this primitive system of vessels.)

Embryological Interpretation.-I shall deal first with the primitive tissue layers and their relation to the above developmental anomalies.

An analysis of the above facts shows that it was those elements within the globe, requiring a special cellular differentiation and the nutritional elements, which were involved in this " arrest" of development.

It will be seen that only those structures derived from certain primary tissues, etc., viz., neural ectoderm, adhesions between 
surface and the neural ectoderm, and the associated paraxial mesoderm were affected.

Neural Ectoderm.-Of all the structures derived from this tissue only the original lining of the optic cup was to be seen, and this in its most primitive state since it never reached the stage of neuronal differentiation (17 mms. embryo stage).

Adhesions between the neural ectoderm and surface tissues.Two structures are derived from this, the vitreous and the suspensory ligament. As previously stated, the vitreous was perfect and it would seem that the suspensory ligament must have either a different derivation from that postulated above, or that this " secondary" vitreous is the basic structure on which is superimposed the "self-determining element," to differentiate "tertiary" vitreous, which is one of the outstanding characteristics of the embryonic ocular tissue.

Associated Paraxial Mesoderm.-Of all the structures derived from this layer, only the most cellular and nutritional elements were absent. These included ciliary muscle, retinal circulation, greater part of the uveal system of vessels, certain orbital vessels which take part in forming the uveal system of vessels and probably the structures in the "angle" of the anterior chamber.

Considering the above developmental anomalies in this left eye, which involved the higher-specialised elements, it is rather wonderful that the "self-determination" of this ocular tissue resulted in an eye at all. It is quite obvious that the mode of development of ocular tissue is not dependent on the association of one tissue with another. The essential factor appears to be the inherent biological determination of individual cell units, reinforced by some local stimulus.

A deductive reasoning to provide clinical "proof " of the origin and development of the vitreous.

The absence of the following structures, viz. :

(1) Ciliary body,

(2) Normal retinal circulation,

indicated that they took no part in the development of the perfect vitreous, $A$.

We have also seen that retinal differentiation did not proceed beyond the $17 \mathrm{mms}$. stage, if it ever reached this stage (1).

The absence of choroid on one side and the undeveloped choroid on the other side, dates the time of the " arrest" of development to the 5 to $6 \mathrm{mms}$. stage of embryonic development (2).

The hyaloid system of vessels begins to develop about this time ( 3 to $5 \mathrm{mms}$. embryo) and in view of the absence of any " remains" of this system of vessels in this primitive eye, the 
non-development of the normal retinal vascular system (an outgrowth from this primitive system) and in the presence of factors (1) and (2) we may say with confidence that this hyaloid system of vessels never developed at all (3).

It follows, therefore, that the vascularisation of the " primary" vitreous is not an essential precursor of adult "secondary" vitreous, $B$.

We cannot say that in the absence of the hyaloid system of vessels the " primary" vitreous is not identical with the " secondary" vitreous (4).

The lens has been shown to be of a primitive type, possessing an auxiliary blood supply and situated in an abnormal position.

It would seem then that, apart from the mere presence of the lens, neither position, degree of development, and its particular metabolism (whether avascular or vascular) had any influence in the development of the perfect vitreous (5).

The main assumption to be drawn is that the lens played but a passive rôle in the development of vitreous, $C$.

The absence of any coarse " primary" vitreous, and the absence of a retinal circulation to absorb it, suggests that the " primary" and the "secondary" vitreous are one and the same thing and that the characters of the " primary" vitreous are overshadowed by its infiltration with the hyaloid system of vessels (6).

" Tertiary " vitreous being absent in this left eye in association with the absence of ciliary body, and the fact that the whole globe was filled with " secondary" vitreous suggests that the "secondary" vitreous is the basis on which the "tertiary", vitreous is differentiated. One might even go so far, in the light of the last paragraph, vide infra, as to say that the ciliary body is responsible and, in particular, its pigmented epithelium (absent in this case) which is but a modification of the original neural ectoderm lining the optic cup (7).

The only structure left to form the " secondary" vitreous is the non-vascular lining of the optic cup, which in view of its immaturity must be due to the functioning of its primitive cells, acting by virtue of their inherent determination and their specialised nature. (The neural ectoderm being the most highly "specialised" of embryonic tissue), $D$.

Clinico-Physiological Interpretation.-We have in this left eye the peculiar phenomenon of normal tension with the absence of the greater part of the mechanism believed to be responsible for its maintenance. There was also a detached retina to complicate the analysis. In the light of the facts available, it would appear that the tension was maintained by the vitreous gel, which completely filled the globe and was supported by the coats of the eyeball. 
The next point of interest is the optical and physical perfection of the vitreous which has been maintained in its augmented state despite the almost complete absence of vascular structures within this eye. Two possibilities suggest themselves, and they are that :

(1) The remnants of the choroid were sufficient to maintain the volume and physical structure of the vitreous at their maximum efficiency (all other vascular structures being absent).

(2) The vitreous when fully determined in development requires no maintenance whatever, and that while hermetically sealed within the globe and not subject to pathological interference retains its efficiency unimpaired.

With regard to the first suggestion, it seems impossible that a choroid lacking capillary development is capable of supporting the vitreous intact by the process of dialysation. It also negatives any suggestion that the vitreous might be supported by the process known, and theoretically interpreted, as the "stagnans aqueous " whereby water and ions pass through the coats of the eye to the vitreous.

We are therefore left with only one alternative, and that is possibility No.2.

With regard to the absence of aqueous, it has been shown that in this peculiar developmental condition of the eye, aqueous is not essential to the maintenance of normal tension. In this respect it must be remembered that this globe was virtually hermetically sealed as the anterior angle and canal of Schlemm had in all probability been developmentally absent. How much the absence of aqueous affected the nutrition of the capsule of the ectopic lens one cannot say with any certainty, but it is interesting to note the clinical report on this which shows that " it had the appearance of thickened, greasy parchment, and possessed an auxiliary blood supply."

In the normal eye the innermost layer of the retina is nourished by the retinal vessels, while the outer layers are nourished by the choriocapillaris, but in this case the retina, lacking neuronal development, was very thin. On the nasal side (undetached portion) the retina appeared to be nourished by the underlying defective choroid. I am not prepared to say how this occurred, since these larger vessels are not supposed to have the same functions as the more intricate choriocapillaris. On the temporal side there was a complete absence of choroid and the retina was detached and the nourishment was apparently derived from the aberrant equatorial vessels.

The lens not having achieved perfection of its metabolism due in part to its defective differentiation, its abnormal position within the globe, and the absence of aqueous, was also forced to draw 
upon the blood vessels from the equatorial region for its structural maintenance. (Preservation of its inherent selfdetermination.)

Ocular Phenomena.-Right eye: There was a marked "proptosis" of the right eye which was produced by the generalised enlargement of this globe and not by any other agency. It was impossible to close the lids over the eye and the whole appearance of the patient's face was rather grotesque. The globe almost wholly filled the external opening to the orbital cavity, and appeared to have a diameter of about one and a half inches. The cornea was normal in size, being $11 \frac{1}{2}$ by $11 \frac{1}{2} \mathrm{mms}$., the circumference being more rounded than is usual and the anterior surface of the cornea, more flattened. There were no localised staphylomata, the whole enlargement being due to a generalised stretching. The centre of the cornea showed evidence of a past keratitis in the central area which was faintly nebulous. There was no evidence of corneal vascularisation.

The conjunctiva overlying the sclera was thinned and showed evidence of chronic hyperaemia with a profusion of dilated blood vessels which appeared to stand out from the thinned conjunctiva. The underlying sclera was abnormally thinned, transparent in places and was of bluish-black colour. The lens was in the normal position and showed fine opacities. On the anterior surface there were fine posterior synechiae with a fair amount of pigment deposition. The pupil diameter was three and a half mms. and there was no pupil reaction to light. What could be seen in the posterior aspects of this globe showed that the vitreous was fluid with large and small floaters, some of which appeared to be in the form of " fixed" wavy vertical strings. The fundus was not seen, but in the lateral zone one could see the region of the ciliary body which showed up, as a dense black band about a disc diameter in width, running circularly round the globe, associated with a mass of greyish tissue just anterior to it and traversing a similar course. This phenomena was well seen on the nasal side, but was seen with great difficulty on the temporal aspect of the globe. The fundus reflex was so bad that a retinoscopy was impossible, but an estimate of the refraction based on the size of the globe was $-35 \mathrm{D}$. The tension at this stage was sub-normal. The ocular movements were seriously curtailed by the size of the globe, by the fact that the muscles were considerably stretched and by the fact that their " physiological points of contact" were situated too posteriorly to permit of the proper action of the muscles.

Certain other points, however, require elucidation. Why did the cornea remain the normal size while the rest of the globe 
underwent generalised stretching? The protective mechanism appeared to be the scleral ring reinforced by the laminated nature of the cornea. In all probability also there was a developmental weakness in the sclera since there were no localised staphylomata, and the portion of this eye which should have given way first should have been the nebulous corneal centre. (There was no evidence of keratoconus in this case.)

For cosmetic reasons the patient was advised to have this blind eye removed, and shortly afterwards was admitted to the Romford Old Church Hospital where an enucleation under evipan was performed by Mr. Collyer Summers.

The following details kindly supplied by Dr. Miles, Medical Superintendent of the Romford Old Church Hospital, indicate the nature and progress of the case while in hospital.

Admitted.-February 7, 1939. Right enucleation under evipan, February 10, 1939. Pre-operative examination showed heart and chest normal. No untoward symptoms during operation.

On February 11, 1939, the patient developed aphasia. Temperature, respiration and pulse normal:

On February 16, 1939: slight rise of temperature, pulse and respiration. T. 99.4\%. P.R. 104. R.R. 22.

February 17, 1939, the temperature dropped to normal. P.R. 100. At this stage the patient was examined by Dr. Plummer, who reported as follows :

"Patient quite co-operative. Right facial paralysis. K.J. plus "Babinski" equals flexor response. Abdominal reflexes plus. Biceps jerks plus. Hearing normal. Understands perfectly. Heart normal. Diagnosis: Right hemiplegia, cause unknown.

The same evening (February 17, 1939) temperature rose to $\cdot 98 \cdot 8^{\circ}$ and continued to rise steeply until death. 1939).

A rash developed on the body the following day (February 18,

Death supervened on February 20, 1939.

A post-mortem examination was made to establish the cause of death, and Dr. Marshall's report in full is given below.

\section{Notes on Post-Mortem Examination}

\section{Chief points in the history of the case}

About six years ago operation on the right eye. Right eye removed here recently. Paralysis : right side- ? duration. Left brachial thrombosis.

External Marks.-Left arm cyanosed. Right eye missing.

Chest and Pleurae.-Negative. 
Heart.-Right ventricle thick walled, mitral stenosis-old. Orifice admits one finger only. Aortic orifice small, striations and early atheroma of the ascending aorta. Recent red, ragged vegetation at the origin of the innominate and carotid.

Lungs.-Some congestion and bronchitis.

Glands.-Negative.

Abdomen.-Stomach, intestines and glands negative.

Liver.-Moderate nutmeg.

Spleen.-Small, recent infarctions at the upper border.

Pancreas.-Negative.

Kidneys.-Right and left negative.

Central Nervous System: Brain.-Yellowish discoloration over the left cortical area. (Parietal.) Haemorrhagic mass between the cortex and the basal ganglia.

? Glioma. ?Thrombosis and haemorrhage. $1^{\prime \prime} 1^{\prime \prime} 2^{\prime \prime}$.

Special points.-No chancre or scar on glans. For section : cerebral mass Hist. 48/39. Section shows a thrombus surrounded by scavenger cells. No infection in the right eye socket. Death from cerebral " tumour." Date : February 21, 1939.

\section{Diagnostic Summary}

This is embodied in the schematic representation showing the age of the patient at which the various lesions developed.

Birth.-Congenital maldevelopment of left eye associated with blindness. (Hereditary.)

Late childhood.-Chronic Endocarditis of mitral and aortic valves. Causal agent unknown.

Early puberty.-Defective physical development secondary to cardiac affection and primary causal agent. (?Rheumatism.)

Late puberty.-Embolic Phenomena complicated by aphasia following a dental operation.

One year later.-Metastatic uveitis with blindness in right eye suddenly intervenes without apparent cause, secondary glaucoma follows. Probable reacerbation of sub-acute bacterial endocarditis, with lodgment of emboli in postciliary arteries and choroid of this region.

Three years later.-Enucleation of grossly enlarged globe performed, followed by aphasia again, but in association with right hemiplegia. Death supervenes. Patient has developed a fulminating malignant endocarditis, complicated by cerebral embolism. The main feature being that the vegetations were attached to the atheromatous aorta and innominate $(\mathrm{L})$ artery, and not to the old sclerosed mitral valves. 


\section{General Summary}

Evidence of certain rare congenital abnormalities is given.

Complex factors operating to produce total blindness in a single patient outlined in detail.

Congenital affections of the globe have been shown to have embryological and developmental significance, when analysed in relation to "time" in development and to the primitive tissue layers.

The development of the vitreous is "proved" by clinical observation.

A strong hereditary tendency to maldevelopment of globe is shown in relation to congenital cerebral maldevelopment in other members of the same family.

Gross cardiac affection has been shown to be present, of long standing, without obvious signs of this condition. The appearance of a fulminating endocarditis without previous evidence of infection and in the presence of an aseptic orbital wound has been demonstrated.

Embolic phenomena following on this endocarditis and terminating fatally have been outlined.

Acknowledgments.-I desire to thank Dr. W. A. Bullough for permission to publish details of this case, to Dr. Miles for records of the case while in the Old Church Hospital and to Messrs. Clement Clarke for their unfailing courtesy and assistance in reproducing my original fundus sketches.

\section{REFERENCES}

\section{Aplasia of Optic Nerves}

HAWLEY, C. W.-Congenital absence of the optic disk. Ophthal. Record, Vol. XX, pp 27-28, 1911

SzYMANSKI.-Les altérations rétiniennes dans l'oeil d'un chat privé de papille. Bull. Soc franc. Ophtal., Vol. XXIX, pp. 265-272, 1926. Brit. Jl. Ophthal., Vol. XXII, No. 11, pp. 669-671, November, 1939.

Briere.-Absence des papilles; cecité absolute. Ann. d'Ocul., Vol. LXXVIII, p. 41,1877 .

\section{Cerebral Defect in Relation to Aplasia of OPTIC NERVE}

Rosenbaum, S. B.-Beiträge zur Aplasie des Nervus opticus. Diss. Morlung, 1902. Also in Zeitschr.f. Augenheilk., Vol. VII, pp. 200-213, 1902. ZEEMAN, W. P. C. and TUMBELAKA, R.-Das zentrale und periphere optische
System bei liner kongenital blinden Katze.

Parsons, Sir John Herbert.-Diseases of Eye. Seventh edition.

DUKE-ELDER, SIR S.-Text-book of Ophthalmology. Vol. II, p. 1341, 1938.

MANN, Miss IDA.-Developmental Abnormalities of the Eye. 1937. 